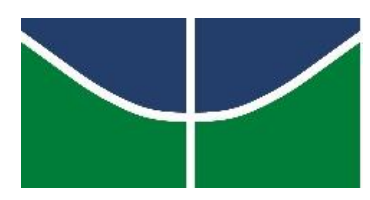

UNIVERSIDADE DE BRASÍLIA

Faculdade de Economia, Administração, Contabilidade e Gestão de Políticas Públicas Departamento de Ciências Contábeis e Atuariais

Bacharelado em Ciências Contábeis

EDUARDO DE JESUS CARVALHO

ANÁLISE FINANCEIRA DAS DEMONSTRAÇÕES CONTÁBEIS DO SERVIÇO BRASILEIRO DE APOIO ÀS MICRO E PEQUENAS EMPRESAS (SEBRAE)

Brasília - DF 


\section{Professora Doutora Márcia Abrahão Moura \\ Reitora da Universidade de Brasília}

\section{Professora Doutora Cláudia da Conceição Garcia \\ Decana de Ensino de Graduação}

\section{Professora Doutora Helena Eri Shimizu}

\section{Decana de Pós-Graduação}

Professor Doutor Eduardo Tadeu Vieira

Diretor da Faculdade de Economia, Administração, Contabilidade e Gestão de Políticas Públicas

Professor Doutor Paulo César de Melo Mendes Chefe do Departamento de Ciências Contábeis e Atuariais

Professor Doutor César Augusto Tibúrcio Silva Coordenador do Programa Pós-graduação em Ciências Contábeis

Professora Doutora Danielle Montenegro Salamone Nunes Coordenador de Graduação do curso de Ciências Contábeis - Diurno

Professor Mestre Elivânio Geraldo de Andrade

Coordenador de Graduação do curso de Ciências Contábeis - Noturno 


\title{
ANÁLISE FINANCEIRA DAS DEMONSTRAÇÕES CONTÁBEIS DO SERVIÇO BRASILEIRO DE APOIO ÀS MICRO E PEQUENAS EMPRESAS (SEBRAE)
}

Trabalho de Conclusão de Curso (Monografia) apresentado ao Departamento de Ciências Contábeis e Atuariais da Faculdade de Economia, Administração, Contabilidade e Gestão de Políticas Públicas da Universidade de Brasília como requisito à conclusão da disciplina Pesquisa em Ciências Contábeis e obtenção do grau de Bacharel em Ciências Contábeis.

\section{Orientadora:}

Prof. ${ }^{a}$ Dr. ${ }^{a}$ Mariana Guerra

\section{Linha de Pesquisa:}

Contabilidade para Tomada de Decisão

\author{
Área de Concentração: \\ Contabilidade Gerencial
}

Brasília 
CARVALHO, Eduardo de Jesus.

Análise das Demonstrações Contábeis do Serviço de Apoio às Micro e Pequenas Empresas - Sebrae.

Orientadora: Prof. ${ }^{\text {a }}$ Dr. ${ }^{a}$ Mariana Guerra

Trabalho de conclusão de curso (Monografia - Graduação) -

Universidade de Brasília, $1^{\circ}$ semestre letivo de 2019.

Bibliografia

1. Análise Financeira; 2. Indicadores; 3. Sistema Sebrae. 


\section{ANÁLISE FINANCEIRA DAS DEMONSTRAÇÕES CONTÁBEIS DO SERVIÇO BRASILEIRO DE APOIO ÀS MICRO E PEQUENAS EMPRESAS (SEBRAE)}

Trabalho de Conclusão de Curso (Monografia) apresentado ao Departamento de Ciências Contábeis e Atuariais da Faculdade de Economia, Administração, Contabilidade e Gestão de Políticas Públicas da Universidade de Brasília como requisito à conclusão da disciplina Pesquisa em Ciências Contábeis e obtenção do grau de Bacharel em Ciências Contábeis.

Prof. Dr. ${ }^{a}$ Mariana Guerra

Professora Orientadora

Universidade de Brasília

Banca Examinadora

Universidade de Brasília 
Dedico este trabalho a minha querida vovó, Osória. A mulher mais forte que tive o prazer de conhecer. 


\section{AGRADECIMENTOS}

Me formar pela Universidade de Brasília é um sonho, concluo essa etapa da minha vida com a sensação de dever cumprido e com o enorme sentimento de gratidão, pelas pessoas e pelos desafios que se tornaram degraus para a minha chegada até aqui.

Agradeço a Deus, pela oportunidade da existência permitindo a vivência de experiências indescritíveis;

Aos amigos que fiz durante toda a minha vida acadêmica, com os quais compartilhei as angústias e as glórias dessa jornada;

Aos amigos feitos fora da sala da aula, pelo aprendizado, pela parceria e por todos os momentos vividos juntos;

A todas as instituições de ensino em que estudei, por terem sido o meu segundo lar e o ambiente de tanto aprendizado;

A todos os professores que passaram pela minha caminhada, em especial a minha professora e orientadora Mariana Guerra, por se doarem a uma profissão tão bonita e serem agentes transformadores de vidas;

Agradeço especialmente a Camila, a Pollyana, ao Tiago, ao Marco, ao Wedson e o ao Paulo, por terem sido a minha família fora de casa;

A minha sobrinha Luíza, que com tão pouco tempo de vida, já transformou a minha;

Aos meus irmãos Fernando e Suzana, por serem os meus maiores exemplos e as primeiras pessoas que me inspiraram quando criança;

Por fim, agradeço aos meus pais, Francisco e Maria, por serem a razão pela qual eu me levanto todos os dias acreditando que eu posso ser uma pessoa melhor.

Palavras nunca serão o suficiente para agradecer a qualquer pessoa que pela minha vida tenha passado e tenha deixado um pouco de si. A vida é mesmo a arte dos encontros. 


\section{RESUMO}

O presente estudo objetiva fazer uma análise financeira de uma empresa com importante papel no desenvolvimento econômico do país, o Serviço Brasileiro de Apoio às Micro e Pequenas Empresas (Sebrae). Dando continuidade a estudos passados, a presente pesquisa busca reavaliar a divulgação contábil da instituição e atestar a situação financeira do Sebrae Nacional e de suas unidades estaduais. A partir de uma abordagem descritiva e quantitativa, os resultados apontaram para uma melhora significativa no nível de divulgação das demonstrações contábeis em decorrência da implantação do portal de transparência do Sebrae. Quanto a avaliação financeira, concluiu-se que o Sistema se encontra em uma boa situação dados os indicadores calculados. Contudo, das unidades avaliadas, o Sebrae do estado do Maranhão (MA) foi o único que se destacou negativamente apresentando resultados insatisfatórios para mais da metade dos indicadores estudados.

Palavras-chave: Análise Financeira, Indicadores, Sistema Sebrae. 


\begin{abstract}
The present study aims to make a financial analysis of an important company for the development of the Brazilian economy, the "Serviço Brasileiro de Apoio às Micro e Pequenas Empresas (Sebrae)". Continuing past studies, this research seeks to reassess the accounting disclosure of the institution and attest to the financial situation of the National Sebrae and your state units. From a descriptive and quantitative approach, the results pointed to a significant improvement in the disclosure level of the financial statements, as a result of the implementation of the Sebrae transparency portal. As regards the financial evaluation, it was concluded that the System is in a good position given the calculated indicators. However, of the evaluated units, the Sebrae of Maranhão (MA) was the only one that stood out negatively presenting unsatisfactory results for more than half of the indicators studied.
\end{abstract}

Keywords: Financial Analysis, Indicators, Sebrae System. 


\section{ÍNDICE QUADROS E TABELAS}

Quadro 1: Fórmula de cálculo dos indicadores financeiros ............................................... 22

Quadro 2: Resumo dos indicadores com resultados insatisfatórios .........................................35

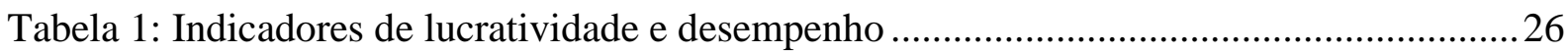

Tabela 2: Indicadores de estrutura de capitais e solvência .................................................. 28

Tabela 3: Indicadores de liquidez e capacidade de pagamento .............................................. 31

Tabela 4: Indicadores de gestão do capital de giro............................................................. 33 


\section{SUMÁRIO}

1. INTRODUÇÃ

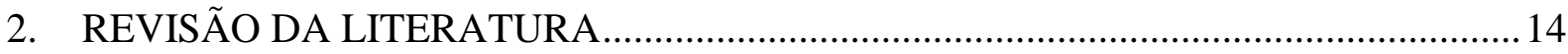

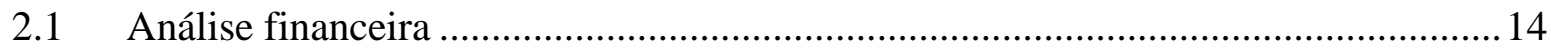

2.2 Análise financeira do Sebrae, Sistema $\mathrm{S}$ e de entidades sem fins lucrativos............. 16

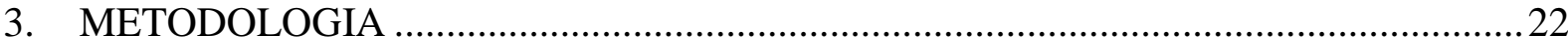

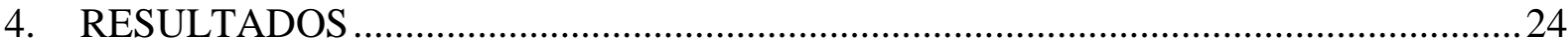

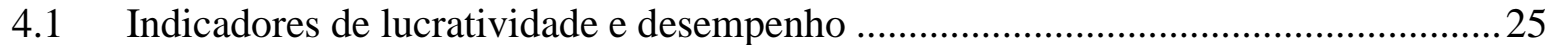

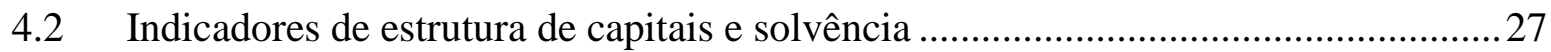

4.3 Indicadores de liquidez e capacidade de pagamento .................................................30

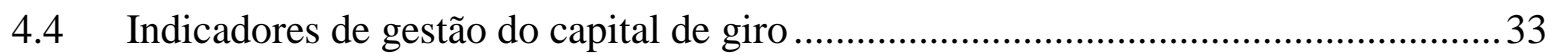

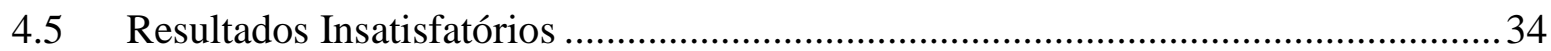

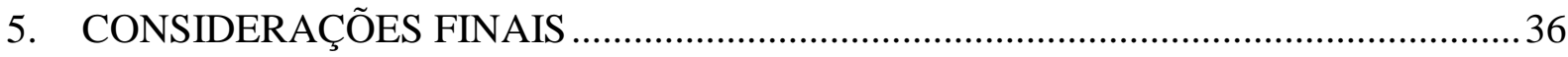

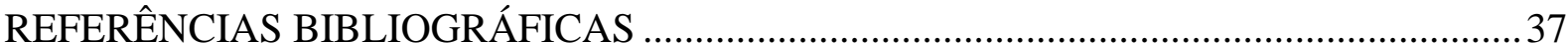




\section{INTRODUÇÃO}

No contexto de atuação e relevância das atividades das micro e pequenas empresas no Brasil (SEBRAE, 2019) foi criado o Serviço Brasileiro de Apoio às Micro e Pequenas Empresas (Sebrae), com o objetivo de promover o crescimento e a capacitação dos pequenos negócios. A entidade atua desde 1972 e trabalha, especificamente, para estimular o empreendedorismo e possibilitar a competitividade e a sustentabilidade dos empreendimentos de micro e pequeno porte (SEBRAE, 2019). O Sebrae está presente nos 27 estados brasileiros e possui uma sede denominada de Sebrae Nacional, que é responsável pelo direcionamento estratégico do sistema, definindo diretrizes e prioridades de atuação. Já as unidades estaduais são as que desenvolvem ações de acordo com a realidade regional e as diretrizes nacionais.

Integrante do grupo de serviços sociais autônomos, também conhecidos como "Sistema S”, estes possuem a responsabilidade de apoiar a Administração Pública e promover ações voltadas, principalmente, à assistência social e à formação profissional (ZANELLA, 2012). Segundo Milhomem (2014), os serviços sociais autônomos são entidades de direito privado, criadas por lei, que desempenham esforços em atividades sociais e de formação profissional que são de interesse de toda a sociedade. Com isso, essas entidades exploram diversas atividades de natureza pública no interesse das respectivas categorias profissionais que representam e possui privilégios próprios das pessoas jurídicas de direito privado. Não têm fins lucrativos (já nasceram do intuito afastado de ter lucro ou prejuízo), e tem uma situação peculiar, pois são consideradas pessoas jurídicas especiais, com o propósito de implementar políticas públicas.

Dado a importância do Sistema $\mathrm{S}$ e de atuação de apoio a Administração Pública, o Tribunal de Contas da União (TCU), entre outras recomendações, determinou por meio do Acórdão $n^{\circ}$ 699/2016 que todas as entidades desse Sistema passassem a divulgar amplamente suas demonstrações contábeis, elaborando-as, no que couber, de acordo com a contabilidade aplicada ao setor público e com o uso concomitante da contabilidade empresarial. Segundo Leão (2017), embora anteriormente algumas unidades do Sistema S já divulgassem seus demonstrativos contábeis, a informação era publicada de forma limitada e não padronizada.

Nesse contexto, o presente estudo, dado continuidade ao trabalho desenvolvido por Leão (2017), objetiva analisar os indicadores financeiros do Sebrae (Nacional e estaduais). Leão (2017) analisou as demonstrações contábeis 2016-2017 do Sebrae, com vistas a contribuir com o fortalecimento do recente processo de transparência. Os resultados encontrados pela autora indicam que o Sebrae não estava em conformidade com as recomendações dos normativos e do 
Comitê de Pronunciamentos Contábeis (CPC), “ainda que aspectos como o prazo, periodicidade e local de publicação tenham sido devidamente atendidos, a divulgação das demonstrações contábeis foi incompleta e insuficiente para proporcionar a leitura contábil da situação patrimonial e financeira por seus usuários" (LEÃO, 2017, p. 47).

Buscando validar tais resultados e complementar os estudos sobre o Sebrae, a relevância do presente trabalho encontra-se na importância da análise financeira, como ferramenta de avaliação de empresas (SILVA, 2012). Para tanto, o trabalho encontra-se dividido em seis seções, iniciando-se com a presente introdução. Na seção 2, apresenta-se a revisão de estudos anteriores que se relacionassem com o Sebrae e com análises financeiras de empresas com características semelhantes às do Sebrae. Na metodologia (seção 3), caracteriza-se a pesquisa como descritiva com uma abordagem quantitativa, e, os resultados (seção 4), tratam dos indicadores analisados. Por fim, tem-se as considerações finais (seção 5), seguidas das referências bibliográficas. 


\section{REVISÃO DA LITERATURA}

A revisão da literatura a respeito do Sebrae contempla artigos nacionais publicados em língua portuguesa no período de 2010 a 2018, selecionados por meio de busca no Google Acadêmico e do Portal de Periódicos CAPES a partir das seguintes palavras-chaves: "Sebrae", "Análise Financeira", "Entidades Paraestatais" e "Terceiro Setor".

Devido a carência de trabalhos com foco específico na análise e/ou avaliação do Sebrae, a revisão da literatura passou a abranger, também, artigos que dissertam sobre a atuação do Sebrae e demais entidades do Sistema S. Ainda como forma de complementar a busca por estudos anteriores, incluíram-se trabalhos que tratam da análise financeira de entidades da mesma natureza do Sebrae, ou seja, que não possuem fins lucrativos. Os resultados de tal revisão são apresentados na Seção 2.1, que descreve os 16 artigos identificados, quais sejam: Teixeira (2010), Barbosa (2010), Campos et al. (2011), Zanella (2012), Milhomen (2014), Martins (2014), Lamachia (2014), Prado e Parayarina (2015), Ralio e Donadone (2015), Guimarães e Guilhaumon (2016), Mendes et al. (2016), Alves (2016), Timotio et al. (2017), Niquito et al. (2018), Martins e Bezerra (2018) e Oliveira et al. (2018).

Separadamente, na Seção 2.2, dissertam-se sobre os trabalhos que tratam de forma abrangente sobre análise financeira, que são: Rezende, Duarte, Silva e Silva (2010), Passaia, Silva, Silva e Demozzi (2011), Ribeiro, Macedo e Marques (2012), Nascimento, Franco e Cherobim (2012), Trindade, Claro, Tinoco e Severo (2013), Lucente e Bressan (2015).

\subsection{Análise financeira}

Rezende, Duarte, Silva e Silva (2010) fizeram uma análise do desempenho financeiro e econômico da Petrobras, empresa de relevância significativa para o cenário brasileiro, no período de 2008 e 2009, baseando a sua análise em indicadores econômico-financeiros, calculados, assim como o presente estudo, a partir das demonstrações contábeis. Sua pesquisa se caracteriza como um estudo de caso descritivo com uma abordagem quantitativa. A coleta de dados foi realizada através das demonstrações contábeis consolidadas publicadas nos sítios da Petrobras e da CVM, referentes aos exercícios de 2008 e 2009. O estudo revelou os principais aspectos sob a ótica da situação financeira e econômica, e os resultados mostraram que a Petrobras superou o período de crise financeira mundial com estabilidade, apresentando uma variação pouco significativa nos índices durante o período analisado. 
Passaia, Silva, Silva e Demozzi (2011) tendo como objeto de estudo uma indústria de alimentos localizada em Nova Mutum no Mato Grosso, realizaram uma análise financeira com o intuito de verificar a sua saúde financeira e apresentar os indicadores financeiros que pudessem auxiliar os gestores da informação na tomada de decisão, abordando os indicadores de liquidez, rentabilidade, lucratividade e prazos médios. Com base no período entre 2005 e 2009, no estudo de caso, utilizaram-se as demonstrações contábeis da empresa. Os autores ressalvam a importância das demonstrações contábeis para a extração de dados importantes para os administradores de uma organização, e após o cálculo dos indicadores, os resultados revelaram que a empresa, ao longo dos anos, vem melhorando o seu índice de liquidez geral e alerta para o cuidado com os capitais de terceiros que se encontra elevado em sua estrutura de capital, e boa parte, vencíveis em curto prazo.

Com um objetivo parecido, Ribeiro, Macedo e Marques (2012) realizaram um estudo buscando analisar a relevância não só dos indicadores financeiros como também dos indicadores não financeiros, no setor brasileiro de distribuição de energia elétrica. Para a concretização do estudo, realizou-se uma pesquisa descritiva e exploratória. Após a seleção de 38 indicadores abrangendo as perspectivas financeiras, operacionais e socioambientais, os pesquisadores elaboraram um questionário para que o respondente apontasse os indicadores mais relevantes e depois, um segundo questionário, que permitissem comparações de cada indicador com todos os outros da mesma perspectiva. Os resultados mostraram que em relação à perspectiva financeira, o indicador mais importante é a Cobertura de Juros, seguido pelo Retorno sobre o Patrimônio Líquido e pelo Perfil de Endividamento. Pelo lado da perspectiva operacional, os autores observaram certo equilíbrio entre os indicadores, como uma leve vantagem para os indicadores de Margem Ebitda (Lucros antes de juros, impostos, depreciação e amortização), DEC (Duração Equivalente de Interrupção por Unidade Consumidora) e FEC (Frequência Equivalente de Interrupção por Unidade Consumidora), que são os três mais importantes. Por fim, a análise da perspectiva socioambiental mostra que a Taxa de Comprometimento Ambiental e a Rentabilidade Agregada dos Investimentos são, respectivamente, os dois indicadores mais relevantes.

Analisando, também, as empresas do setor de energia elétrica, Nascimento, Franco e Cherobim (2012) fizeram um estudo com o objetivo de avaliar se neste setor existe relação entre os índices contábeis financeiros e as práticas de remuneração variável. Com uma pesquisa de natureza descritiva, o estudo compara dados de um mesmo ano para as diferentes empresas do setor e a análise de dados é quali-quantitativa. O estudo explora as demonstrações contábeis das 49 empresas que possuíam as informações disponíveis e que atuam nas atividades de geração, 
transmissão, distribuição, comercialização e holdings do setor elétrico brasileiro, para a realização do cálculo dos índices de lucratividade e rentabilidade. Após a elaboração de algumas hipóteses para o estudo, os resultados mostraram que a remuneração variável evidenciada no relatório da administração por empresas do setor elétrico não pode ser considerada um fator que satisfaz o empregado - segundo os pesquisadores, não há diferenciação relevante o suficiente entre os componentes da amostra que divulgam participação nos resultados e nos lucros comparativamente àqueles que não o fazem.

Voltando a falar dos indicadores financeiros e não financeiros, Trindade, Claro, Tinoco e Severo (2013), se propuseram a avaliar a importância desses na tomada de decisões gerenciais. Através de uma pesquisa exploratória, os autores utilizaram como referência uma pesquisa bibliográfica de trabalhos desenvolvidos por pesquisadores que têm apresentado contribuições efetivas do estudo do uso dos indicadores financeiros e não financeiros na tomada de decisões gerenciais. Os autores destacaram a figura do BSC (Balanced Scorecard), que, apesar de ser uma excelente ferramenta que abrange indicadores não financeiros, não dispensa os indicadores financeiros e nem pode substituir a contabilidade tradicional. Com isso, concluíram que os indicadores financeiros, para a tomada de decisões, devem ser empregados juntamente com os indicadores de tendências, se tornando assim uma ferramenta precisa para decisões de curto, médio e longo prazo.

No âmbito dos esportes, Lucente e Bressan (2015) realizaram um estudo, cujo objetivo principal foi analisar os indicadores financeiros do Sport Club Corinthians Paulista no período de 2008 a 2013. Para atender os objetivos da pesquisa, foi utilizada predominantemente uma abordagem qualitativa e a coleta de dados foi realizada por meio do levantamento das Demonstrações Contábeis e outros documentos do Sport Club Corinthians Paulista, disponibilizadas no sítio do clube. Os resultados do estudo revelaram que após a adoção de um novo modelo de gestão administrativa e uma consequente readequação nos aspectos financeiros o clube se tornou rentável, passando de deficitário a superavitário. Quanto aos índices financeiros, conclui-se que, embora apresentasse alto grau de endividamento e baixo grau de solvência, o Sport Club Corinthians Paulista revelou tendências de melhora nos índices de Composição do Endividamento e Liquidez Geral.

\subsection{Análise financeira do Sebrae, Sistema $\mathrm{S}$ e de entidades sem fins lucrativos}

Teixeira (2010) fez uma análise financeira de uma organização, localizada no Rio Grande do Sul, do ramo de vigilância e portaria. O estudo de caso, com abordagem exploratória, 
compreendeu o levantamento de dados econômicos e financeiros da empresa, além de entrevista junto ao administrador para tratar dos instrumentos de controle financeiro, dos custos e das demonstrações contábeis da empresa. As análises das demonstrações contábeis da empresa nos anos de 2007 a 2009 mostraram que a empresa baixou sua lucratividade e aumentou seu endividamento, além da falta de liquidez ao longo do período analisado. A pesquisa revelou ainda que o principal problema da empresa, no período analisado, foi o capital de giro.

Barbosa (2010) analisou os demonstrativos financeiros como um instrumento de gerenciamento para micro e pequenos empreendedores. Através de uma revisão da literatura, o autor discute a importância de se realizar análises das demonstrações contábeis para a sobrevivência do microempreendedor. Tomando como exemplo algumas demonstrações fictícias, o autor faz o cálculo de alguns indicadores financeiros. Com isso, observa que apesar de ter seu uso incentivado por vários autores, a análise de demonstrativos ainda é pouco utilizada como instrumento de planejamento e orçamento nas empresas.

Visto que o Sebrae é uma instituição, cujo principal objetivo é fomentar o desenvolvimento de micro e pequenas empresas (MPE), Campos et al. (2011) analisaram a atuação do Sebrae no estímulo à internacionalização de MPE à luz das teorias sobre internacionalização de empresas. Trata-se de uma pesquisa exploratória, cujos dados foram obtidos por meio de notícias de jornais e de entrevista semiestruturada. A análise dos dados possibilitou concluir que a luz das teorias de internacionalização de empresas discutidas no trabalho, a atuação do Sebrae no sentido de estimular a internacionalização de Micro e Pequenas Empresas é de assessoramento.

Dado que empresas dos serviços sociais autônomos recebem contribuições do dinheiro público, Zanella (2012) se aprofundou na importância da Lei Transparência e seu impacto no Sistema S. A autora fez uma análise da legislação e suas variáveis, destacando a importância de se divulgar as informações e de ser uma instituição transparente, ressalvando os benefícios, para a comunidade. Conclui que a Lei Complementar $n^{\circ} 131 / 09$, lei que acrescenta dispositivos à lei da transparência, foi de grande importância e contribuição para o aumento da transparência desse grupo de empresas, contudo, o grau de transparência é ainda insatisfatório. Segundo Zanella (2012), o Brasil é um país que não carece de legislação quanto ao assunto, e sim de administradores que cumpram a legislação tornando possível o rastreio de todo o destino do dinheiro público.

Alguns autores se preocuparam em estudar sobre as especificidades do Sebrae e do grupo em que está inserido. Tido como uma invenção brasileira, e, portanto, dado a dificuldade de enquadramento de uma empresa do Sistema S, Milhomem (2014) propõe discutir a respeito 
das definições do que seria uma entidade integrante de tal Sistema e das obrigações com o Estado. Após uma análise a respeito do enquadramento dessas entidades, o autor conclui que apesar de serem pessoas jurídicas de direito privado, as entidades do Sistema $\mathrm{S}$ tem o dever indeclinável de prestar contas ao TCU e que prestar contas, afinal, é demonstrar a correta e regular aplicação dos recursos públicos.

Considerando ainda as peculiaridades deste grupo de instituições, Martins (2014) questiona se deve ser aplicado o benefício da imunidade tributária previsto no art. $150 \mathrm{VI}, \mathrm{c}$ da Constituição Federal às empresas do Sistema S. Em relação ao Sebrae, que é um agente executor da política federal e assim, presta um serviço de assistência social especialmente em favor de determinadas classes a que o Estado tenha resolvido amparar de maneira singular, o autor conclui que a instituição é uma entidade de assistência social, podendo assim gozar das imunidades que lhes são próprias.

Visto que a imunidade tributária do Sebrae é um tema que enseja várias interpretações e posições, na mesma linha do artigo anterior, Lamachia (2014) discute a possibilidade legal do Sistema Sebrae obter a declaração de imunidade tributária. Após analisar a imunidade tributária prevista na Constituição Federal, nos artigos 150, VI, 'c" e 195, $\S 7^{\circ}$ e fazer reflexões acerca do posicionamento do Sebrae enquanto entidade e suas atribuições, o autor conclui que o Sebrae enquadra-se no conceito de entidade educacional e de assistência social e sua formatação jurídico-institucional, como Serviço Social Autônomo, sem fins lucrativos, atendendo aos requisitos do artigo 14 do Código Tributário Nacional, podendo, dessa forma, disfrutar de imunidade tributária.

Prado e Paravarina (2015) realizaram um estudo de caso que buscou estudar a atuação do Sebrae do estado de São Paulo (SEBRAE/SP) no desenvolvimento de políticas públicas municipais de apoio às MPE no âmbito do Escritório Regional de Franca (ER-Franca), no período de 2006 a 2015. Por meio de análise documental, o estudo concluiu que existe uma relação direta do Sebrae com as políticas públicas em prol das MPE no município de Franca. Com o apoio e a intervenção do Sebrae, estas obtiveram uma série de vantagens, colocando a cidade de Franca em rankings quanto a formalização de microempreendedor individual (MEI), servindo de referência para os demais municípios.

Analisando as formas de atuação do Sebrae, Ralio e Donadone (2015) buscaram corroborar sobre a atuação do Sebrae de consultoria brasileiro, principalmente no que se refere a sua relação com as micro e pequenas empresas. Para tanto, realizaram uma pesquisa exploratória, utilizando de revisão bibliográfica sobre o tema e de realização de entrevistas semiestruturadas com funcionários, consultores e ex-presidentes da instituição. Os autores 
fizeram uma análise qualitativa, pela ordem cronológica dos dados. Os resultados mostram que no campo da consultoria, as ações do Sebrae são constantes, desde sua fundação; porém não são ações implementadas de forma isolada. Em seus projetos e programas ao longo de sua história, consultoria e treinamento sempre caminharam juntos. Com isso, os resultados demonstram que a instituição possui diversas formas de atuação, como fornecimento de técnicas de gestão, e treinamento, mas também com apoio para participação em eventos e preparação para exportação, além do seu papel de articulação junto ao meio político.

Guimarães e Guillaumon (2016), por sua vez, analisaram projetos criados pelo Sebrae, especificamente o denominado "Compre do Pequeno Negócio", com o propósito de entender qual o potencial de inserção efetiva do mesmo em feiras comerciais locais. A relevância do estudo foi justificada pela crescente abertura de novos empreendimentos no país, tanto formais quanto informais. Por meio de um estudo de caso qualitativa e dedutiva, os autores coletaram dados por análise documental, observação participante no Sebrae durante a Feira do Guará e aplicação de questionários semiestruturados exploratório aos feirantes. A análise dos dados permitiu explorar alguns resultados, como: a maioria dos respondentes tem pouco conhecimento do programa em análise; fizeram-se reflexões quanto à abordagem do Sebrae junto aos lojistas, dado que a maioria demonstra certa desconfiança com instituições externas; e, por fim, notou-se certa desunião dos lojistas, o que fragiliza o desenvolvimento da feira local.

Mendes et al. (2016) apresentaram um diagnóstico realizado no Sebrae no tocante às práticas de Gestão de Conhecimento utilizadas para disseminar, garantir e divulgar os conhecimentos existentes em sua organização. Foram realizadas entrevistas entre os participantes do comitê gestor, além de uma pesquisa eletrônica encaminhada para os Sebrae estaduais para realizar um diagnóstico sobre as práticas existentes de gestão do conhecimento na organização, a partir dos conhecimentos considerados críticos, e do grau de maturidade neste processo. Os resultados mostram que é necessário um aprofundamento da discussão dos conhecimentos críticos da empresa, discutindo-se quais são as temáticas de maior relevância para os pequenos negócios, quais são as práticas observadas no Sistema Sebrae nestes conhecimentos específicos e qual o fluxo para disseminação do conhecimento ideal a ser adotado.

Alves (2016) propôs uma reflexão acerca de como o empreendedorismo levado a cabo pelo Sebrae tem incorporado e difundido a ética do empreendedorismo cultural, e questiona ainda como o Sebrae tem se tornado um dos principais agentes de difusão e legitimação do empreendedorismo cultural no Brasil. Tendo em vista que a instituição é um dos principais agentes estatais de mercado e levando em consideração que as micro e pequenas empresas 
representam 96\% do total de empresas do país, sendo assim responsável pela criação de empregos e gerar renda, o Sebrae é um agente que orienta as tomadas de decisão, instrumentaliza técnicas de gestão e concorre diretamente para a consecução de novos modelos de negócios junto aos micro e pequenos empreendedores culturais.

Analisando uma empresa sem fins lucrativos, Timotio et al. (2017) fizeram uma análise financeira de uma organização do terceiro setor, mais especificadamente a organização não governamental (ONG) Centro Popular de Cultura e Desenvolvimento (CPCD) com o objetivo de avaliar seu desempenho econômico-financeiro. A pesquisa possui caráter descritivo e quantitativo, utilizou-se de pesquisa bibliográfica e documental, bem como o Balanço Patrimonial e Demonstração de Resultado da ONG CPCD. Os resultados da análise dos indicadores possibilitaram concluir que a ONG se encontra com uma boa saúde financeira, possibilitando a sua continuidade e a realização de suas atividades fins.

Niquito et al. (2018) procuraram avaliar se a prestação de serviços de assistência técnica das entidades vinculadas ao Sistema $S$ afeta indicadores de mercado de trabalho de microempreendedores. A metodologia utilizada foi de estimação de modelos de escore de propensão aplicados a amostras complexas. Os resultados obtidos mostram que o recebimento de assistência técnica por parte das entidades do Sistema S aumenta em mais de 40 pontos percentuais (pp) a probabilidade de formalização e em cerca de $20 \mathrm{pp}$ a probabilidade de o microempreendedor buscar crédito. Também tem impactos positivos de $17 \%$ a $22 \%$ sobre a jornada de trabalho semanal e de $20 \%$ a $27 \%$ sobre os rendimentos. Os resultados são mais expressivos entre as mulheres, em comparação aos homens. Não foram encontrados efeitos estatisticamente significativos para o impacto da assistência sobre a obtenção de crédito e sobre a probabilidade de os indivíduos terem mais de um emprego.

Martins e Bezerra (2018) avaliaram a relação entre a percepção de importância dos artefatos da contabilidade gerencial por parte dos colaboradores do Sebrae e a eficácia da execução orçamentária em suas unidades no Brasil. Se trata de um estudo quantitativo, com coleta de dados por meio questionário, em que se utilizou a metodologia chamada SEM (Structural Equation Modeling) para investigar a relação entre as variáveis latentes e para testar a interação moderadora entre essas variáveis. O resultado da pesquisa encontrou evidências de que as ferramentas modernas de contabilidade gerencial quando aplicadas juntas ao modelo de gestão melhoram o desempenho da execução orçamentária.

Por fim, Oliveira et al. (2018) buscaram identificar as percepções dos empreendedores e consultores em relação à prestação de serviço do Sebrae na gestão dos micro e pequenos empreendedores que utilizam os serviços de consultoria. Nessa pesquisa quantitativa, com 
coleta de dados por meio de questionário respondidos por empresários e por meio de entrevistas junto a consultores, os resultados obtidos mostram que a percepção que ambos os usuários possuem da consultoria ofertada pelo Sebrae é favorável para que as empresas se mantenham no mercado; entretanto, para que a consultoria seja aproveitada, os empresários devem seguir corretamente todas as orientações e não apenas as tributárias, mas também as gerenciais. 


\section{METODOLOGIA}

A pesquisa aqui desenvolvida tem natureza descritiva e abordagem quantitativa (TRIVIÑOS, 1987; FONSECA, 2002), em que a coleta de dados se deu por meio do sítio eletrônico do Sebrae, em que estão acessíveis as demonstrações contábeis do Sebrae Nacional e das unidades estaduais. Dado essa disponibilização de dados, foi realizado o "checklist", conforme o estudo de Leão (2017), para fazer a avaliação da divulgação contábil. Por fim, após a padronização das contas dos Balanços Patrimoniais, conforme plano de contas sugerido por Silva (2012), foi possível calcular os indicadores financeiros (ver Quadro 1), também conforme referencial de Silva (2012).

Quadro 1: Fórmula de cálculo dos indicadores financeiros

\begin{tabular}{|c|c|c|}
\hline Grupo & Indicador & Fórmula de cálculo \\
\hline \multirow{4}{*}{ Lucratividade e desempenho } & GA & Receita Líquida / Ativo total \\
\hline & RSV & $\frac{\text { Lucro Líquido }}{\text { Receita Líquida }} \times 100$ \\
\hline & RSA & $\frac{\text { Lucro Líquido }}{\text { Ativo Total }} \times 100$ \\
\hline & RSPL & $\frac{\text { Lucro Líquido }}{\text { (Pat. Líquido - Lucro Líquido) }} \times 100$ \\
\hline \multirow{3}{*}{ Estrutura de capitais e solvência } & IPL & $\frac{\text { Ativo Permanente }}{\text { Patrimônio Líquido }} \times 100$ \\
\hline & PCT & $\frac{\text { Passivo Circ.+Passivo Não Circ. }}{\text { Patrimônio Líqido }} \times 100$ \\
\hline & CEN & $\frac{\text { Passivo Circulante }}{\text { Passivo Circ. + Passivo Não Circ. }} \times 100$ \\
\hline \multirow[t]{4}{*}{ Liquidez e capacidade de pagamento } & LG & Ativo Circulante / (Passivo Circulante + Não Circulante) \\
\hline & $\mathrm{LC}$ & Ativo Circulante / Passivo Circulante \\
\hline & $\mathrm{LS}$ & $\frac{\text { Disponível }+ \text { Ap. Financ }(\mathrm{CP})+\text { Dup .a Receber }}{\text { Passivo Circulante }}$ \\
\hline & ICJ & Lucro líquido / Despesas financeiras \\
\hline Capital de giro & CCL & Ativo Circulante - Passivo Circulante \\
\hline
\end{tabular}

Fonte: baseado em Silva (2012). Legenda: Giro do Ativo - GA; Retorno sobre Vendas - RSV; Retorno sobre o Ativo - RSA; Retorno sobre o Patrimônio Líquido - RSPL, Imobilização do Patrimônio Líquido - IPL; Participação do Capital de Terceiros - PCT, Composição do Endividamento - CEN, Liquidez Geral - LG; Liquidez Corrente - LC; Liquidez Seca - LS, Índice de Cobertura de Juros - ICJ, Capital Circulante Líquido CCL.

A seleção desses indicadores se deu por conta das informações disponíveis - apenas demonstrações contábeis de 2017 e 2018 (ou seja, há dados disponíveis apenas dos exercícios de 2016, 2017 e 2018) e por particularidades do Sebrae quais sejam: (i) entidade sem fins 
lucrativos e uma situação peculiar, tais como as demais do Sistema $S$, que são consideradas pessoas jurídicas especiais, com o propósito de implementar políticas públicas; e (ii) empresa que não possui o seu faturamento proveniente de vendas. Para tratamento dos dados, utilizouse o Microsoft Excel ®. 


\section{RESULTADOS}

O presente estudo dá continuidade ao trabalho de Leão (2017), quem, conforme mencionado na Introdução (Seção 1), analisou as demonstrações contábeis 2016-2017 do Sebrae. A autora identificou alguns problemas no processo de divulgação contábil da entidade, tais como a inexistência de notas explicativas, da Demonstração das Mutações do Patrimônio Líquido (DMPL), da Demonstração dos Fluxos de Caixa (DFC) e da Demonstração do Resultado Abrangente (DRA) no exercício de 2016. No presente estudo, especificamente, busca-se reavaliar a divulgação contábil do Sebrae, bem como analisar os indicadores financeiros dessa entidade, para o período de 2016 a 2018.

Assim, em conformidade com Leão (2017), inicialmente fez-se um "check-list" das demonstrações financeiras que foram divulgadas para o período analisado. Leão (2017), que analisou especificamente o período de 2016 e os três primeiros trimestres do ano de 2017, identificou que a maioria dos Sebrae estaduais não divulgou, por exemplo, as Notas Explicativas de 2016. Fazendo uma nova listagem da divulgação das demonstrações financeiras no mês de agosto de 2018, observou-se uma melhora no nível de disclosure. A divulgação das demonstrações para o ano de 2016 foram ruins e quase inexistentes para a maioria dos estados, diferente das demonstrações do ano de 2017 e dos dois primeiros trimestres de 2018 que foram divulgadas quase em sua totalidade.

No mês de fevereiro de 2019, fez-se uma nova checagem, constando uma melhora considerável da divulgação das demonstrações contábeis. As demonstrações do ano de 2016, que antes não estavam no portal da transparência, em fev/2019 já se encontram disponíveis, assim como as demonstrações anuais do ano de 2017 e 2018, com exceção de algumas demonstrações, quais sejam: a Demonstração de Resultados Abrangentes (DRA) e o Balanço Orçamentário (BO), que não estavam disponíveis, pontualmente, em alguns anos para alguns estados. Com este nível de divulgação encontrado, conclui-se que, desde os estudos de Leão (2017), o nível de divulgação do Sebrae melhorou de forma considerável, permitindo assim, neste estudo, fazer a análise financeira da empresa utilizando as demonstrações divulgadas.

Tal melhora pode ser explicada pelo surgimento do portal da transparência no ano de 2018. Com este portal, se reúnem todas as demonstrações financeiras de todos os Sebraes (estaduais e nacional), proporcionando um ambiente de mais fácil acesso para o usuário de informação. Assim, em sequência, apresentam-se os resultados dos cálculos dos indicadores e suas respectivas análises, por grupo: (4.1) Lucratividade e desempenho; (4.2) Estrutura de capital e solvência; (4.3) Liquidez e capacidade de pagamento; e, (4.4) Gestão do capital de 
giro. Importante ressaltar, novamente, as particularidades do Sebrae, já mencionadas na Seção 3 (Metodologia) que limitam o cálculo de alguns indicadores, bem como delimita a análise desta entidade.

\subsection{Indicadores de lucratividade e desempenho}

Fazem parte do grupo de indicadores de lucratividade e desempenho, conforme Silva (2012): Giro do Ativo - GA, Retorno sobre Vendas - RSV, Retorno sobre o Ativo - RSA, Ativo sobre Patrimônio Líquido - ASPL, e Retorno sobre o Patrimônio Líquido - RSPL. Desses, apenas Ativo sobre Patrimônio Líquido - ASPL não foi mensurado, dado a impossibilidade de cálculo dos valores médios de ativo total e patrimônio líquido - conforme mencionado na Seção 3 (Metodologia), os dados estão disponíveis apenas para os exercícios de 2016, 2017 e 2018. A partir da análise das demonstrações disponíveis dos anos de 2016 a 2018, e do cálculo de indicadores, os resultados para o grupo de lucratividade e desempenho são apresentados na Tabela 1.

O Giro do Ativo (GA) é um dos principais indicadores da atividade de uma empresa, e, segundo Silva (2012), estabelece a relação entre as vendas do período pesquisado e os investimentos totais efetuados na empresa, que estão representados pelo ativo total. Pegando como exemplo o Sebrae do Amazonas (AM) no ano de 2018, obtém-se um giro de 1,22, o que quer dizer que para cada $\mathrm{R} \$ 100,00$ de ativo total, gerou-se $\mathrm{R} \$ 122,00$ de receita durante o ano. Dada a interpretação do índice de "quanto maior, melhor", destacam-se os Sebrae de Distrito Federal (DF), Pará (PA), Paraíba (PB), Rio de Janeiro (RJ), Santa Catarina (SC) e Tocantins (TO) por apresentarem índices maiores do que "dois", sendo considerado por este indicador um excelente resultado. Por sua vez, os Sebrae de Roraima (RR), São Paulo (SP) e o próprio Sebrae Nacional não apresentaram bons resultados para este índice, constando valores menores que "um" para todos os anos analisados.

O índice de Retorno Sobre as Vendas (RSV) compara o lucro líquido em relação as vendas líquidas do período, fornecendo assim o percentual que a entidade está obtendo em relação ao seu faturamento. Silva (2012) ressalva que a interpretação deste indicador é no sentido de que "quanto maior, melhor". Apesar do Sebrae não possuir receita proveniente de vendas, calculando este indicador é possível identificar o percentual de lucro que as unidades estão obtendo em relação as suas receitas. Por essa perspectiva, destacam-se dois Sebrae estaduais que mantiveram índices altos durante os anos estudados, quais sejam: Roraima (RR) e São Paulo (SP). Por outro lado, Alagoas (AL), Amapá (AP), Bahia (BA), Mato Grosso (MT), 
Maranhão (MA), Pará (PA), Paraíba (PB), Pernambuco (PE) e Rondônia (RO), apresentaram, pelo menos, um índice negativo para os anos analisados, com destaque negativo para Maranhão (MA) que manteve o seu índice menor do que "um" para os três anos analisados.

Tabela 1: Indicadores de lucratividade e desempenho

\begin{tabular}{|c|c|c|c|c|c|c|c|c|c|c|c|c|}
\hline \multirow{3}{*}{$\frac{\text { UF }}{\text { Ano }}$} & \multicolumn{12}{|c|}{ Indicadores de lucratividade e desempenho } \\
\hline & \multicolumn{3}{|c|}{ GA } & \multicolumn{3}{|c|}{ RSV } & \multicolumn{3}{|c|}{ RSA } & \multicolumn{3}{|c|}{ RSPL } \\
\hline & 2016 & 2017 & 2018 & 2016 & 2017 & 2018 & 2016 & 2017 & 2018 & 2016 & 2017 & 2018 \\
\hline Nacional & 0,89 & 0,83 & 0,79 & $7,37 \%$ & $13,73 \%$ & $2,07 \%$ & $6,55 \%$ & $11,39 \%$ & $1,64 \%$ & $8,14 \%$ & $15,04 \%$ & $1,92 \%$ \\
\hline $\mathbf{A C}$ & 1,29 & 0,97 & 0,89 & $9,25 \%$ & $8,36 \%$ & $7,21 \%$ & $11,97 \%$ & $8,08 \%$ & $6,41 \%$ & $17,79 \%$ & $12,25 \%$ & $9,66 \%$ \\
\hline $\mathbf{A L}$ & 1,37 & 1,25 & 1,36 & $13,65 \%$ & $6,51 \%$ & $-0,43 \%$ & $18,75 \%$ & $8,11 \%$ & $-0,58 \%$ & $37,53 \%$ & $13,63 \%$ & $-0,85 \%$ \\
\hline $\mathbf{A M}$ & 1,48 & 1,13 & 1,22 & $10,67 \%$ & $5,02 \%$ & $4,03 \%$ & $15,85 \%$ & $5,67 \%$ & $4,91 \%$ & $22,53 \%$ & $8,23 \%$ & $6,65 \%$ \\
\hline $\mathbf{A P}$ & 1,77 & 1,75 & 1,82 & $12,49 \%$ & $3,24 \%$ & $-0,40 \%$ & $22,06 \%$ & $5,69 \%$ & $-0,72 \%$ & $37,30 \%$ & $7,67 \%$ & $-0,88 \%$ \\
\hline BA & 1,83 & 1,80 & 1,36 & $9,64 \%$ & $1,11 \%$ & $-0,02 \%$ & $17,65 \%$ & $2,00 \%$ & $-0,03 \%$ & $34,84 \%$ & $3,12 \%$ & $-0,05 \%$ \\
\hline CE & 1,22 & 1,09 & 1,15 & $3,85 \%$ & $6,99 \%$ & $12,86 \%$ & $4,68 \%$ & $7,64 \%$ & $14,76 \%$ & $6,98 \%$ & $12,04 \%$ & $21,26 \%$ \\
\hline DF & 2,06 & 1,98 & 1,86 & $8,22 \%$ & $8,79 \%$ & $8,89 \%$ & $16,97 \%$ & $17,37 \%$ & $16,54 \%$ & $33,10 \%$ & $30,26 \%$ & $24,28 \%$ \\
\hline ES & 1,42 & 1,00 & 1,11 & $21,50 \%$ & $12,19 \%$ & $3,70 \%$ & $30,45 \%$ & $12,19 \%$ & $4,09 \%$ & $78,01 \%$ & $24,99 \%$ & $6,52 \%$ \\
\hline GO & 1,72 & 1,45 & 1,45 & $13,19 \%$ & $9,93 \%$ & $4,58 \%$ & $22,63 \%$ & $14,36 \%$ & $6,64 \%$ & $45,14 \%$ & $27,66 \%$ & $9,73 \%$ \\
\hline MA & 1,38 & 1,34 & 1,56 & $-1,11 \%$ & $-3,68 \%$ & $-6,56 \%$ & $-1,54 \%$ & $-4,93 \%$ & $-10,21 \%$ & $-2,42 \%$ & $-8,35 \%$ & $-17,61 \%$ \\
\hline MG & 1,10 & 1,10 & 1,23 & $8,67 \%$ & $6,58 \%$ & $2,19 \%$ & $9,53 \%$ & $7,24 \%$ & $2,68 \%$ & $19,97 \%$ & $14,78 \%$ & $4,47 \%$ \\
\hline MS & 1,37 & 1,25 & 1,14 & $14,01 \%$ & $6,94 \%$ & $9,06 \%$ & $19,25 \%$ & $8,67 \%$ & $10,34 \%$ & $32,97 \%$ & $12,35 \%$ & $14,56 \%$ \\
\hline MT & 0,97 & 1,01 & 1,03 & $13,32 \%$ & $-2,65 \%$ & $2,66 \%$ & \begin{tabular}{|l|}
$12,87 \%$ \\
\end{tabular} & $-2,66 \%$ & $2,76 \%$ & $16,92 \%$ & $-3,23 \%$ & $3,44 \%$ \\
\hline PA & 2,57 & 2,37 & 2,19 & $-0,88 \%$ & $1,56 \%$ & $7,84 \%$ & $-2,28 \%$ & $3,69 \%$ & $17,19 \%$ & $-4,12 \%$ & $8,24 \%$ & $38,09 \%$ \\
\hline PB & 2,24 & 2,16 & 1,94 & $6,64 \%$ & $7,42 \%$ & $-1,00 \%$ & $14,88 \%$ & $16,03 \%$ & $-1,95 \%$ & $30,66 \%$ & $31,46 \%$ & $-3,08 \%$ \\
\hline PE & 1,82 & 1,66 & 1,78 & $12,70 \%$ & $10,42 \%$ & $-1,68 \%$ & $23,11 \%$ & $17,29 \%$ & $-3,00 \%$ & $41,98 \%$ & $26,04 \%$ & $-3,51 \%$ \\
\hline PI & 1,19 & 1,12 & 1,01 & $4,56 \%$ & $9,60 \%$ & $6,69 \%$ & $5,42 \%$ & $10,75 \%$ & $6,79 \%$ & $13,89 \%$ & $28,83 \%$ & $15,25 \%$ \\
\hline PR & 1,42 & 1,27 & 1,27 & $17,21 \%$ & $5,07 \%$ & $7,51 \%$ & $24,53 \%$ & $6,43 \%$ & $9,57 \%$ & $38,65 \%$ & $8,74 \%$ & $12,40 \%$ \\
\hline RJ & 2,19 & 1,97 & 2,57 & $7,06 \%$ & $0,08 \%$ & $3,68 \%$ & $15,50 \%$ & $0,17 \%$ & $9,46 \%$ & $25,18 \%$ & $0,29 \%$ & $13,29 \%$ \\
\hline RN & 1,14 & 1,13 & 1,29 & $12,00 \%$ & $6,61 \%$ & $2,83 \%$ & $13,65 \%$ & $7,49 \%$ & $3,65 \%$ & $23,02 \%$ & $12,08 \%$ & $4,99 \%$ \\
\hline RO & 1,32 & 1,15 & 1,06 & $63,97 \%$ & $-4,92 \%$ & $1,33 \%$ & $33,65 \%$ & $-4,58 \%$ & $1,09 \%$ & $63,97 \%$ & $-4,92 \%$ & $1,33 \%$ \\
\hline $\mathbf{R R}$ & 0,97 & 0,70 & 0,58 & $39,96 \%$ & $18,71 \%$ & $16,73 \%$ & $38,57 \%$ & $13,01 \%$ & $9,66 \%$ & $68,84 \%$ & $15,99 \%$ & $11,42 \%$ \\
\hline RS & 1,68 & 1,52 & 1,47 & $12,11 \%$ & $7,74 \%$ & $3,92 \%$ & $20,32 \%$ & $11,76 \%$ & $5,76 \%$ & $38,50 \%$ & $18,38 \%$ & $7,94 \%$ \\
\hline SC & 2,36 & 2,22 & 2,32 & $2,27 \%$ & $7,39 \%$ & $4,45 \%$ & $5,37 \%$ & $16,42 \%$ & $10,31 \%$ & $13,15 \%$ & $43,34 \%$ & $17,83 \%$ \\
\hline SE & 1,25 & 1,22 & 1,34 & $4,33 \%$ & $10,96 \%$ & $0,85 \%$ & $5,42 \%$ & $13,37 \%$ & $1,14 \%$ & $11,38 \%$ & $26,67 \%$ & $1,59 \%$ \\
\hline SP & 0,77 & 0,49 & 0,42 & $48,93 \%$ & $39,95 \%$ & $32,68 \%$ & $37,76 \%$ & $19,63 \%$ & $13,81 \%$ & $72,65 \%$ & $27,34 \%$ & $17,04 \%$ \\
\hline TO & 1,96 & 2,03 & 1,64 & $10,41 \%$ & $7,87 \%$ & $5,95 \%$ & $20,37 \%$ & $15,94 \%$ & $9,78 \%$ & $42,67 \%$ & $25,36 \%$ & $13,21 \%$ \\
\hline
\end{tabular}

Fonte: elaboração própria. Legenda: Giro do Ativo - GA; Retorno sobre Vendas - RSV; Retorno sobre o Ativo RSA; Retorno sobre o Patrimônio Líquido - RSPL; UF - Unidade da Federação; AC - Acre; AL - Alagoas; AM - Amazonas; AP - Amapá; BA - Bahia; CE - Ceará; DF - Distrito Federal; ES - Espírito Santos; GO - Goiás; MA - Maranhão; MG - Minas Gerais; MS - Mato Grosso do Sul; MT - Mato Grosso; PA - Pará; PB - Paraíba; PE - Pernambuco; PI - Piauí; PR - Paraná; RJ - Rio de Janeiro; RN - Rio Grande do Norte; RO - Rondônia; RR - Roraima; RS - Rio Grande do Sul; SC - Santa Catarina; SE - Sergipe; SP - São Paulo; TO - Tocantins.

O indicador de Retorno Sobre o Ativo (RSA) indica a lucratividade que a empresa proporciona em relação aos investimentos totais (SILVA, 2012), representados, neste estudo, pelo ativo total. Assim como no índice anterior, os Sebrae de Alagoas (AL), Amapá (AP), Bahia (BA), Mato Grosso (MT), Maranhão (MA), Pará (PA), Paraíba (PB), Pernambuco (PE) e Rondônia (RO), apresentaram, pelo menos, um índice negativo devido aos déficits, fazendo com que o indicador se torne negativo. Em contrapartida, obtiveram bons resultados, os Sebrae 
de Distrito Federal (DF), Mato Grosso do Sul (MS) e São Paulo (SP). É interessante destacar Ceará (CE) e Pará (PA) que apesar de não terem tanto destaque, ou até apresentarem índices negativos (estado do Pará (PA) no ano de 2016) nos anos anteriores, no ano de 2018 apresentaram resultados expressivos para este indicador.

O índice que diz respeito ao retorno sobre o patrimônio líquido (RSPL), segundo Silva (2012), indica o valor do prêmio em que os acionistas ou proprietários da empresa estão logrando em relação aos seus investimentos no empreendimento, ou seja, este indicador se refere à capacidade em agregar valor utilizando dos próprios recursos. Mais uma vez, os Sebrae de Alagoas (AL), Amapá (AP), Bahia (BA), Mato Grosso (MT), Maranhão (MA), Pará (PA), Paraíba (PB), Pernambuco (PE) e Rondônia (RO), apresentaram, pelo menos, um índice negativo por motivos já mencionados no índice anterior. Destacam-se, com bons resultados para este indicador Distrito Federal (DF), Mato Grosso do Sul (MS), Piauí (PI), Roraima (RR), Santa Catarina (SC) e São Paulo (SP). Novamente Ceará (CE) e Pará (PA), no ano de 2018 apresentaram resultados expressivos para este indicador.

De uma forma geral, o Sebrae se encontra em uma posição confortável em relação a esse grupo de indicadores, salvo algumas exceções. Para o Giro do Ativo, os resultados apresentam em sua maioria, resultados melhores para o ano de 2016 e em seguida para o ano de 2018. Os outros índices de retorno indicam melhores resultados para o de ano de 2016. A preocupação maior para este grupo de indicadores está no Sebrae do Maranhão (MA), que apesar de ter apresentado um índice positivo para o Giro do Ativo, foi a única unidade com resultados negativos para os três indicadores de retorno, por apresentar resultados deficitários para os três anos analisados.

\subsection{Indicadores de estrutura de capitais e solvência}

Fazem parte do grupo de indicadores de estrutura de capitais e solvência, conforme Silva (2012): Imobilização do Patrimônio Líquido - IPL, Participação de Capitais de Terceiros PCT, Composição do Endividamento - CEN, Endividamento Financeiro Sobre Ativo Total EFSAT, e Nível de Desconto de Duplicadas - NDD. Desses, apenas Endividamento Financeiro Sobre Ativo Total - EFSAT e Nível de Desconto de Duplicadas - NDD não foram calculados dado o baixo nível de detalhamento na divulgação das demonstrações financeiras. A partir da análise das demonstrações disponíveis dos anos de 2016 a 2018, e do cálculo de indicadores, os resultados para o grupo estrutura de capitais e solvência são apresentados na Tabela 2. 
Tabela 2: Indicadores de estrutura de capitais e solvência

\begin{tabular}{|c|c|c|c|c|c|c|c|c|c|}
\hline \multirow{3}{*}{$\frac{\text { UF }}{\text { Ano }}$} & \multicolumn{9}{|c|}{ Indicadores de Estrutura de Capitais e Solvência } \\
\hline & \multicolumn{3}{|c|}{ IPL } & \multicolumn{3}{|c|}{ PCT } & \multicolumn{3}{|c|}{ CEN } \\
\hline & 2016 & 2017 & 2018 & 2016 & 2017 & 2018 & 2016 & 2017 & 2018 \\
\hline Nacional & $3,44 \%$ & $2,69 \%$ & & $14,94 \%$ & & $15,05 \%$ & $71,04 \%$ & $84,54 \%$ & $70,58 \%$ \\
\hline AC & & & & & & & & & \\
\hline $\mathbf{A L}$ & & $4,78 \%$ & & & & & & $89,76 \%$ & \\
\hline AM & & $0,72 \%$ & & $5,86 \%$ & $4,26 \%$ & &, $41 \%$ & $73,65 \%$ & \\
\hline $\mathbf{A F}$ & & $65,85 \%$ & & & & & & $88,59 \%$ & \\
\hline BA & & & & & & & & $82,42 \%$ & \\
\hline & & & & & & & & & \\
\hline & & 2 & & & & & & & \\
\hline ES & & $88,31 \%$ & & & & & & $7 \%$ & \\
\hline GC & & $34,32 \%$ & & $37,41 \%$ & & & & $76,24 \%$ & \\
\hline & & 77,6 & & & & & & & \\
\hline $\mathbf{M}$ & & & & & & & & $4 \%$ & \\
\hline & & & & & & & & & \\
\hline & & & & & & & & & \\
\hline $\mathbf{P}$ & & 32 & & & & & & $77 \%$ & \\
\hline PI & &, $66 \%$ & & $66 \%$ & & & & $72,96 \%$ & \\
\hline PE & & $4,07 \%$ & & $7,93 \%$ & & & & $94,72 \%$ & \\
\hline PI & & $67,75 \%$ & & $125,09 \%$ & $108,15 \%$ & & & $27,98 \%$ & $18,41 \%$ \\
\hline PR & & & & & & & & & \\
\hline & & & & & & & & & \\
\hline & & & & & & & & & \\
\hline & & $44 \%$ & & & & $71 \%$ & & $95,75 \%$ & 78,1 \\
\hline $\mathbf{R}$ & & $28,46 \%$ & & $5,72 \%$ & & & $00 \%$ & $97,29 \%$ & \\
\hline $\mathbf{R}$ & & $12,08 \%$ & & $36,77 \%$ & $04 \%$ & $27,72 \%$ & $77,77 \%$ & $81,75 \%$ & $79,41 \%$ \\
\hline SC & $122,90 \%$ & $81,73 \%$ & & $116,46 \%$ & & $46,82 \%$ & $76,09 \%$ & $56,40 \%$ & $85,85 \%$ \\
\hline SE & & & & & & & & $78,46 \%$ & \\
\hline & & & & & & & & $69,87 \%$ & \\
\hline TO & $56,09 \%$ & $44,36 \%$ & $37,62 \%$ & $46,80 \%$ & $26,91 \%$ & $19,35 \%$ & $67,00 \%$ & $82,72 \%$ & $73,89 \%$ \\
\hline
\end{tabular}

Fonte: elaboração própria. Legenda: IPL -Imobilizado do Patrimônio Líquido PCT - Participação de Capitais de Terceiros; CEN - Composição do Endividamento. UF - Unidade da Federação; AC - Acre; AL - Alagoas; AM Amazonas; AP - Amapá; BA - Bahia; CE - Ceará; DF - Distrito Federal; ES - Espírito Santo; GO - Goiás; MA - Maranhão; MG - Minas Gerais; MS - Mato Grosso do Sul; MT - Mato Grosso; PA - Pará; PB - Paraíba; PE Pernambuco; PI - Piauí; PR - Paraná; RJ - Rio de Janeiro; RN - Rio Grande do Norte; RO - Rondônia; RR Roraima; RS - Rio Grande do Sul; SC - Santa Catarina; SE - Sergipe; SP - São Paulo; TO - Tocantins.

O índice de Imobilização do Patrimônio Líquido (IPL), segundo Silva (2012) indica o quanto do patrimônio líquido da empresa está aplicado no ativo permanente. Do ponto de vista do risco, a interpretação geral deste índice é de quanto maior for a porcentagem, pior será para a empresa, afinal, representa o quanto a empresa está dependente de recursos de terceiros para a manutenção dos seus negócios. Analisando os resultados, o Sebrae Nacional, encontra-se com o melhor índice, destacando-se também Paraná (PR), Rio Grande do Sul (RS) e São Paulo (SP), com valões por volta de, ou abaixo de, $15 \%$ para os três anos analisados. Os Sebrae do Distrito Federal (DF), Pará (PA), Pernambuco (PE), Rio de Janeiro (RJ), Rondônia (RO) e Roraima (RR) também demonstraram bons índices, apresentando uma imobilização do patrimônio líquido de no máximo $40 \%$ para o período estudado. Por outro lado, os Sebrae do Acre (AC), 
Bahia (BA), Espírito Santos (ES), Maranhão (MA), Minas Gerais (MG) e Santa Catarina (SC) revelaram índices preocupantes, em alguns casos ultrapassando 100\%. Os demais, apresentaram um declínio nos índices ou uma constante baixa, fora de preocupação.

O índice de Participação de Capitais de Terceiros (PCT) indica o percentual de capital de terceiros em relação ao patrimônio líquido, retratando a dependência da empresa em relação aos recursos externos. A interpretação deste índice não é um processo fácil, mas pode ser simplificada para fins de análise financeiras, segundo Silva (2012), para quanto maior, pior. Com este indicador, é possível observar quanto a empresa tomou de capitais de terceiros em relação ao seu capital próprio. Para os resultados encontrados, o Sebrae de Roraima (RR) é o que apresenta o melhor indicador, junto a São Paulo (SP) e o Sebrae Nacional, que apresentam, no máximo, uma porcentagem de $15 \%$ de participação de capitais de terceiros. Os Sebrae de Amapá (AP), Mato Grosso do Sul (MS), Mato Grosso (MT), Pernambuco (PE), Paraná (PR) e Rondônia (RO) também apresentaram índices bons, sendo que nenhum ultrapassa 30\% de participação de capitais de terceiros. Em contrapartida, outros Sebrae estaduais demonstraram índices elevados de participação de recursos de terceiros, por exemplo: no caso da Bahia (BA) que ultrapassa 100\% de participação; e, Maranhão (MA), Minas Gerais (MG), Piauí (PI), Rio de Janeiro (RJ) e Santa Catarina (SC), que apesar de terem demonstrado uma queda significativa no indicador, no ano de 2016 revelou uma participação de $116 \%$ de capitais de terceiros em relação ao capital próprio.

O índice de Composição do Endividamento (CEN) mostra quanto da dívida total da entidade deverá ser paga a curto prazo. Sua finalidade é identificar o perfil do endividamento, ou seja, o percentual das obrigações a curto prazo comparadas com as obrigações totais. Mantendo a interpretação dos indicadores anteriores, de que quanto maior os resultados, pior para a organização, apenas os Sebrae da Bahia (BA), Espírito Santo (ES), Maranhão (MA) e Piauí (PI) revelaram resultados que se encontram abaixo dos 50\%. O estado do Acre (AC) e de Roraima (RR), para o ano de 2016, revelam uma composição de endividamento de $100 \%$, explicado pela falta de passivos de longo prazo nas demonstrações financeiras.

Analisando o grupo de indicadores de estrutura de capital e solvência, a maioria das unidades apresenta bons índices, ou valores não preocupantes para os indicadores de imobilização do patrimônio líquido e de participação de capital de terceiros. Entretanto, o Sebrae pode estar em uma situação de risco em relação a composição do endividamento ao apresentar significativa concentração no Passivo Circulante (MARION, 2017), uma vez que a maioria das suas unidades apresentam resultados elevados para este indicado. Ou seja, a entidade poderá ter reais dificuldades num momento de reversão de mercado, dificuldade que 
não teria se as dívidas estivessem concentradas no longo prazo, e, portanto, mais tempo para replanejar as suas estratégias financeiras. Os três indicadores, apresentaram os melhores resultados para o ano de 2018, de forma geral. Os destaques negativos são das unidades do Maranhão (MA), que embora tenha apresentado uma baixa composição do endividamento, apresentou crescimentos consideráveis para os demais indicadores, e também para Minas Gerais (MG), que apesar de ter apresentado uma baixa nos indicadores durante o período analisado, continua apresentando resultados preocupantes para este grupo de indicadores.

\subsection{Indicadores de liquidez e capacidade de pagamento}

Fazem parte do grupo de indicadores de liquidez e capacidade de pagamento, conforme Silva (2012): Liquidez Geral - LG, Liquidez Corrente - LC, Liquidez Seca - LS, Índice de Cobertura de Juros - ICJ e Saldo de Tesouraria Sobre Vendas - STSV. Desses, apenas o Saldo de Tesouraria Sobre Vendas - STSV, não foi calculado por ser um indicador que busca analisar o volume de vendas e sendo o Sebrae uma entidade que não aufere receita através de vendas. A partir da análise das demonstrações disponíveis dos anos de 2016 a 2018, e do cálculo de indicadores, os resultados para o grupo liquidez e capacidade de pagamento são apresentados na Tabela 3.

Silva (2012) diz que o índice de Liquidez Geral (LG) mostra quanto a empresa possui em dinheiro, bens e direitos realizáveis a curto e longo prazo, para poder arcar com suas dívidas totais. De certa forma, este indicador representa a capacidade em honrar deveres e compromissos, se a entidade fosse encerrar os negócios naquele momento. Neste estudo, foi considerado apenas os recursos de curto prazo em frente ao seu passivo total. Silva (2012) também ressalva que a análise para este indicador é no sentido de quanto maior, melhor. É interessante observar que a Liquidez Geral (LG) é um indicador oposto ao da Imobilização do

Patrimônio Líquido (IPL), ou seja, quando um deles cresce, o outro decresce. Com isso, os resultados obtidos demonstraram resultados parecidos com os resultados do indicador de Imobilização do Patrimônio Líquido (IPL), em que o Sebrae Nacional demonstrou o melhor resultado. Os Sebrae de Paraná (PR), Pernambuco (PE), Rondônia (RO), Roraima (RR) e São Paulo (SP) também apresentaram resultados expressivos para os três anos de estudo. Por não apresentarem nenhum resultado acima de 1, os Sebrae do Maranhão (MA) e do Piauí (PI) são as unidades que demonstraram não conseguir fazer face das suas dívidas totais se parassem as suas atividades, segundo a análise deste indicador. 
Tabela 3: Indicadores de liquidez e capacidade de pagamento

\begin{tabular}{|c|c|c|c|c|c|c|c|c|c|c|c|c|}
\hline \multirow{3}{*}{$\frac{\text { UF }}{\text { Ano }}$} & \multicolumn{12}{|c|}{ Indicadores de liquidez e capacidade de pagamento } \\
\hline & \multicolumn{3}{|c|}{ LG } & \multicolumn{3}{|c|}{ LC } & \multicolumn{3}{|c|}{\begin{tabular}{|c|} 
LS \\
\end{tabular}} & \multicolumn{3}{|c|}{ ICJ } \\
\hline & 2016 & 2017 & 2018 & 2016 & 2017 & 2018 & 2016 & 2017 & 2018 & 2016 & 2017 & 2018 \\
\hline Nacional & 7,24 & 7,26 & 7,24 & 10,19 & 8,58 & 10,26 & 6,33 & 5,11 & 6,44 & 0,00 & 34205,57 & 4399,63 \\
\hline AC & 4,54 & 2,19 & 1,68 & 4,54 & 4,01 & 3,38 & 3,75 & 2,73 & 2,40 & 7,90 & 28,79 & 86,30 \\
\hline $\mathbf{A L}$ & 2,12 & 2,15 & 1,95 & 2,36 & 2,39 & 2,69 & 1,81 & 1,49 & 1,68 & 70,38 & 29,24 & $-2,25$ \\
\hline $\mathbf{A M}$ & 3,74 & 2,42 & 2,79 & 3,76 & 3,29 & 4,03 & 2,32 & 1,68 & 2,66 & 111,84 & 92,70 & 45,14 \\
\hline AP & 1,84 & 2,17 & 2,24 & 2,30 & 2,44 & 3,04 & 1,40 & 0,88 & 1,24 & 0,00 & 9,02 & $-1,81$ \\
\hline BA & 2,42 & 2,34 & 1,24 & 2,80 & 2,84 & 2,89 & 2,20 & 1,87 & 2,06 & 14,96 & 1,32 & $-0,03$ \\
\hline $\mathbf{C E}$ & 1,72 & 1,97 & 3,82 & 2,65 & 2,64 & 5,90 & 1,90 & 1,60 & 3,56 & 4,07 & 7,45 & 17,20 \\
\hline DF & 2,37 & 3,17 & 5,31 & 2,41 & 3,26 & 5,92 & 1,67 & 1,93 & 4,64 & 17,51 & 34,27 & 31,08 \\
\hline ES & 2,08 & 1,02 & 0,87 & 3,67 & 2,68 & 2,79 & 2,45 & 1,27 & 1,32 & 47,84 & 12,05 & 2,68 \\
\hline GO & 2,65 & 2,21 & 3,03 & 2,93 & 2,90 & 4,14 & 2,02 & 1,73 & 3,03 & 77,37 & 51,05 & 9,31 \\
\hline MA & 0,26 & 0,54 & 0,94 & 0,72 & 1,32 & 4,21 & 0,04 & 0,03 & 2,14 & $-0,19$ & $-39,06$ & $-65,35$ \\
\hline MG & 0,86 & 1,06 & 1,20 & 1,40 & 1,44 & 1,87 & 0,85 & 0,64 & 1,31 & 5,16 & 26,66 & 6,71 \\
\hline MS & 2,16 & 2,52 & 3,19 & 3,59 & 4,09 & 5,53 & 2,80 & 2,63 & 4,42 & 22,03 & 10,17 & 17,22 \\
\hline MT & 4,10 & 2,49 & 2,87 & 5,15 & 3,37 & 3,45 & 4,47 & 2,48 & 2,72 & 11,45 & $-3,57$ & 16,38 \\
\hline PA & 1,69 & 1,56 & 2,15 & 2,31 & 2,43 & 3,42 & 1,63 & 1,15 & 2,07 & $-17,59$ & 29,43 & 138,32 \\
\hline PB & 1,74 & 2,06 & 1,79 & 2,58 & 2,83 & 2,97 & 1,80 & 1,56 & 1,96 & 19,46 & 29,04 & $\begin{array}{l}-4,57 \\
\end{array}$ \\
\hline PE & 3,42 & 4,89 & 4,46 & 3,61 & 5,17 & 4,69 & 2,97 & 3,40 & 3,26 & 133,16 & 100,51 & $\begin{array}{l}-8,88 \\
\end{array}$ \\
\hline PI & 0,54 & 0,68 & 0,71 & 1,66 & 2,44 & 3,84 & 1,21 & 1,28 & 2,38 & 1,95 & 4,31 & 3,29 \\
\hline PR & 5,97 & 3,75 & 6,79 & 7,08 & 5,71 & 10,99 & 5,68 & 4,08 & 8,67 & 97,73 & 21,78 & 15,32 \\
\hline RJ & 1,89 & 1,77 & 1,90 & 2,22 & 2,12 & 2,53 & 1,39 & 1,03 & 1,42 & 46,17 & 0,43 & 11,86 \\
\hline $\mathbf{R N}$ & 1,87 & 1,90 & 2,36 & 2,64 & 2,41 & 2,93 & 1,87 & 1,61 & 1,77 & 78,13 & 21,45 & 12,75 \\
\hline RO & 3,34 & 2,23 & 3,71 & 3,56 & 2,33 & 4,74 & 0,58 & 0,68 & 3,25 & 547,32 & $-25,35$ & 8,54 \\
\hline RR & 5,90 & 3,54 & 13,25 & 6,07 & 3,54 & 13,34 & 5,12 & 1,58 & 11,70 & 744,58 & 206,09 & 100,07 \\
\hline RS & 3,07 & 3,51 & 3,87 & 3,76 & 4,51 & 4,88 & 3,09 & 3,03 & 3,73 & 59,23 & 27,55 & 17,31 \\
\hline SC & 0,80 & 1,21 & 1,72 & 1,42 & 1,59 & 2,00 & 0,81 & 0,60 & 0,98 & 2,07 & 152,56 & 104,45 \\
\hline SE & 1,37 & 1,79 & 2,32 & 1,74 & 2,20 & 2,60 & 1,51 & 1,57 & 1,91 & 25,72 & 167,87 & 17,27 \\
\hline SP & 1,58 & 3,91 & 17,16 & 2,27 & 5,49 & 18,77 & 0,34 & 4,29 & 10,39 & 658,56 & 187,00 & 51,05 \\
\hline TO & 1,94 & 3,07 & 4,22 & 2,34 & 4,57 & 5,72 & 1,38 & 2,33 & 3,76 & 111,66 & 57,05 & 37,26 \\
\hline
\end{tabular}

Fonte: elaboração própria. Legenda: LG - Liquidez Geral; LC - Liquidez Corrente; LS - Liquidez Seca; ICJ Índice de Cobertura de Juros. UF - Unidade da Federação; AC - Acre; AL - Alagoas; AM - Amazonas; AP Amapá; BA - Bahia; CE - Ceará; DF - Distrito Federal; ES - Espírito Santo; GO - Goiás; MA - Maranhão; MG - Minas Gerais; MS - Mato Grosso do Sul; MT - Mato Grosso; PA - Pará; PB - Paraíba; PE - Pernambuco; PI Piauí; PR - Paraná; RJ - Rio de Janeiro; RN - Rio Grande do Norte; RO - Rondônia; RR - Roraima; RS - Rio Grande do Sul; SC - Santa Catarina; SE - Sergipe; SP - São Paulo; TO - Tocantins.

Ao tratar da Liquidez Corrente (LC) Silva (2012) diz que os números indicam quanto a empresa possui em caixa e em bens e direitos realizáveis a curto prazo, comparando as suas dívidas a serem pagas também no curto prazo, ou seja, este indicador demonstra a capacidade de pagamento da empresa no curto prazo. Com os resultados obtidos, é possível observar que o Sebrae Nacional e do Paraná (PR) foram as unidades que se destacaram por apresentarem resultados bastante elevados, acima de 5, para os três anos analisados. Apresentando bons resultados para, pelo menos, dois anos do período analisado, destacaram-se os Sebrae de Roraima (RR) e São Paulo (SP). O Sebrae do Ceará (CE), Mato Grosso (MT) e Mato Grosso do Sul (MS), apresentaram, pelo menos, em um ano, resultados maiores que 5. O destaque negativo para este indicador, é somente para o Sebrae do Maranhão (MA), que foi a única 
unidade que apresentou, neste índice, resultado menor que 1, apesar de ter aumentado significativamente o seu resultado com o passar dos anos.

A Liquidez Seca (LS), segundo Silva (2012), é um indicador que procura mostrar quanto a empresa possui em disponibilidades (dinheiro, depósitos bancários a vista e aplicações financeiras de liquidez imediata), aplicações financeiras a curto prazo e duplicatas a receber, para fazer face a seu passivo circulante. Para o cálculo deste indicador, no estudo, considerouse as contas de "Disponível", "Aplicações Financeiras de Curto Prazo" e "Duplicatas a Receber". Se trata de um indicador parecido com o de liquidez corrente, mas, mais restrito. Após a análise dos resultados, é possível perceber que novamente o Sebrae Nacional se destaca entre as outras unidades a juntamente com o Sebrae do Paraná (PR), por ambos apresentarem indicadores elevados em relação às demais. Os Sebrae de Maranhão (MA), Minas Gerais (MG), Rondônia (RO) e Santa Catarina (SC), por sua vez, não apresentaram resultados satisfatórios para este indicador, apresentando resultados abaixo de 1 para, pelo menos, dois anos dentro do período analisado.

O Índice de Cobertura de Juros (ICJ), segundo Silva (2012), relaciona o lucro antes dos juros e impostos com as despesas financeiras da empresa no período, como uma maneira de identificar a sua capacidade de pagar suas despesas financeiras. O Sebrae Nacional e o Sebrae do Amapá (AP), no ano de 2016, apresentaram resultados iguais a 0 para este indicador, por não demonstrar nenhum valor de Despesas Financeiras em suas demonstrações. Apesar disso, o Sebrae Nacional demonstrou números bastante elevados quando comparado as demais unidades. Os Sebrae de Roraima (RR) e São Paulo (SP) foram as únicas unidades a apresentaram resultados expressivos durante os três anos analisados no estudo. Contudo, a atenção vai para os Sebrae estaduais que possuem resultados negativos, demonstrando um lucro menor do que suas despesas financeiras, quais sejam: Alagoas (AL), Amapá (AP), Maranhão (MA), Mato Grosso do Sul (MS), Mato Grosso (MT), Pernambuco (PE) e Rondônia (RO) todos com pelo menos um resultado negativo, com exceção do Maranhão (MA), que apresentou resultado negativo para todos os anos.

Fazendo uma análise deste grupo de indicadores, é possível notar algumas constantes. O Sebrae Nacional se mantém com bons resultados para todos os índices deste grupo de indicadores, enquanto o Sebrae do Maranhão (MA), mantém resultados insatisfatórios. Com exceção dessa unidade estadual, as demais não apresentaram resultados considerados preocupantes para este grupo de indicadores. Embora existam resultados insatisfatórios para algumas unidades, tais resultados não se mantêm constantes em todos os indicadores, assim como ocorre no Sebrae do Maranhão (MA). 


\subsection{Indicadores de gestão do capital de giro}

Fazem parte do grupo de indicadores de gestão de capital de giro conforme Silva (2012): Capital Circulante Líquido - CCL, Capital Permanente Líquido - CPL, Capital de Giro Próprio - CGP e Capital de Giro Operacional Líquido - CGOL. Desses, somente o Capital Circulante Líquido - CCL foi calculado, por apresentar paridade com o escopo do estudo, os demais indicadores não foram considerados pertinentes de análise devido as particularidades da entidade. A partir da análise das demonstrações disponíveis dos anos de 2016 a 2018, e do cálculo de indicadores, os resultados para o grupo gestão de capital de giro são apresentados na Tabela 4.

Tabela 4: Indicadores de gestão do capital de giro

\begin{tabular}{|c|c|c|c|}
\hline \multirow{3}{*}{$\frac{\text { UF }}{\text { Ano }}$} & \multicolumn{3}{|c|}{ Indicadores de Gestão de Capital de Giro } \\
\hline & \multicolumn{3}{|c|}{ CCL } \\
\hline & 2016 & 2017 & 2018 \\
\hline Nacional & 3.103 .897 & 3.507 .011 & 3.669 .231 \\
\hline $\mathrm{AC}$ & 17.318 & 16.973 & 14.305 \\
\hline $\mathbf{A L}$ & 14.899 & 18.286 & 17.328 \\
\hline $\mathbf{A M}$ & 16.173 & 23.237 & 23.647 \\
\hline $\mathbf{A P}$ & 3.892 & 5.651 & 6.015 \\
\hline $\mathbf{B A}$ & 37.002 & 41.165 & 43.076 \\
\hline $\mathbf{C E}$ & 25.687 & 34.125 & 49.485 \\
\hline DF & 13.425 & 20.122 & 26.975 \\
\hline ES & 23.854 & 18.395 & 13.263 \\
\hline GO & 26.593 & 38.438 & 43.968 \\
\hline MA & -2.048 & 2.962 & 14.473 \\
\hline MG & 19.433 & 30.730 & 43.538 \\
\hline MS & 18.247 & 23.258 & 31.364 \\
\hline MT & 29.398 & 30.458 & 29.913 \\
\hline PA & 14.301 & 17.655 & 23.079 \\
\hline PB & 10.566 & 14.823 & 16.386 \\
\hline $\mathbf{P E}$ & 29.816 & 41.920 & 39.246 \\
\hline PI & 4.954 & 10.414 & 13.656 \\
\hline PR & 69.271 & 83.374 & 113.803 \\
\hline RJ & 36.719 & 40.209 & 34.667 \\
\hline $\mathbf{R N}$ & 16.416 & 20.750 & 21.085 \\
\hline RO & 13.426 & 5.501 & 20.471 \\
\hline RR & 12.356 & 7.724 & 42.214 \\
\hline $\mathbf{R S}$ & 58.281 & 72.856 & 76.663 \\
\hline SC & 6.619 & 13.026 & 16.372 \\
\hline SE & 9.747 & 13.448 & 12.688 \\
\hline SP & 72.000 & 272.061 & 939.077 \\
\hline TO & 8.540 & 13.270 & 15.717 \\
\hline
\end{tabular}

Fonte: elaboração própria. Legenda: CCL - Capital Circulante Líquido. UF - Unidade da Federação; AC - Acre; AL - Alagoas; AM - Amazonas; AP - Amapá; BA - Bahia; CE - Ceará; DF - Distrito Federal; ES - Espírito Santo; GO - Goiás; MA - Maranhão; MG - Minas Gerais; MS - Mato Grosso do Sul; MT - Mato Grosso; PA Pará; PB - Paraíba; PE - Pernambuco; PI - Piauí; PR - Paraná; RJ - Rio de Janeiro; RN - Rio Grande do Norte; RO - Rondônia; RR - Roraima; RS - Rio Grande do Sul; SC - Santa Catarina; SE - Sergipe; SP - São Paulo; TO - Tocantins. 
O Capital Circulante Líquido (CCL) consiste na diferença entre o ativo circulante e o passivo circulante. Segundo Silva (2012) existem duas possibilidades de classificar este capital, quando o ativo circulante é maior que o passivo circulante, entende-se que a empresa possui um capital circulante líquido próprio; e, quando o contrário acontece, o ativo circulante é menor que o passivo circulante, a empresa possui um capital circulante líquido negativo ou de terceiros. Com isto, é possível verificar que todas as unidades do Sistema Sebrae possuem um capital circulante líquido próprio, com exceção de um estado. Os Sebrae do Amapá (AP), Maranhão (MA), Piauí (PI) e Sergipe (SE), se encontram com os piores resultados calculados pelo índice, embora sejam positivos, com exceção do Maranhão (MA) em 2016, nenhum destes estados ultrapassou o valor de 15 mil para o capital circulante líquido nos três anos analisados.

O Sebrae Nacional, em destaque, apresentou o melhor resultado para este indicador, ultrapassando o valor de 3 milhões em todos os anos. Além dessa unidade, destaca-se positivamente os Sebrae do Paraná (PR), Rio Grande do Sul (RS) e São Paulo (SP), por apresentarem resultados superiores a 50 mil em todos o período analisado.

Com os resultados obtidos por este indicador, é possível afirmar que o Sebrae se encontra fora de preocupação no que se refere ao seu capital circulante líquido. Mesmo o Sebrae do Maranhão (MA), que se destacou negativamente no ano de 2016, apresentou uma melhora

significativa nos anos posteriores. É relevante destacar que das 28 unidades do Sistema Sebrae, 21 unidades apresentaram um aumento neste indicador, 5 mantiveram os seus resultados e somente 2 apresentaram um declínio no período analisado.

\subsection{Resultados Insatisfatórios}

Os resultados da análise financeira das demonstrações das unidades do Sistema Sebrae podem ser sumarizados no Quadro 2. A interpretação das informações na referida Tabela considera a marcação de ' $\mathrm{X}$ ' na unidade do Sistema Sebrae que demonstrou, no mínimo, dois resultados insatisfatórios dentre os três possíveis anos analisados para o indicador.

Pela análise horizontal do Quadro 2, observa-se o Sebrae do Maranhão (MA) é o que se destaca negativamente com o maior número (9) de indicadores de resultados insatisfatórios, seguido de Minas Gerais (MG) com 4 resultados, Santa Catarina (SC) com 3, Piauí (PI) com 2 e, por fim o Sebrae Nacional, Acre (AC), Bahia (BA), Espírito Santo (ES), Rio de Janeiro (RJ), Rondônia (RO), Roraima (RR) e São Paulo com 1 cada. Com isso, ressaltam-se que 15 unidades do Sistema Sebrae, pouco mais da metade, não obtiveram nenhum resultado insatisfatório para os 12 índices calculados neste estudo. 
Quadro 2: Resumo dos indicadores com resultados insatisfatórios

\begin{tabular}{|c|c|c|c|c|c|c|c|c|c|c|c|c|}
\hline \multirow{2}{*}{$\mathbf{U F}$} & \multicolumn{12}{|c|}{ Resultados Insatisfatórios } \\
\hline & GA & RSV & RSA & RSPL & IPL & PCT & CEN & LG & $\mathbf{L C}$ & LS & ICJ & CCL \\
\hline Nacional & $\mathrm{x}$ & & & & & & & & & & & \\
\hline $\mathrm{AC}$ & & & & & $\mathrm{x}$ & & & & & & & \\
\hline \multicolumn{13}{|l|}{$\mathbf{A L}$} \\
\hline \multicolumn{13}{|l|}{$\mathbf{A M}$} \\
\hline \multicolumn{13}{|l|}{$\mathbf{A P}$} \\
\hline $\mathbf{B A}$ & & & & & & $\mathrm{x}$ & & & & & & \\
\hline \multicolumn{13}{|l|}{$\mathbf{C E}$} \\
\hline \multicolumn{13}{|l|}{ DF } \\
\hline ES & & & & & $\mathrm{x}$ & & & & & & & \\
\hline \multicolumn{13}{|l|}{ GO } \\
\hline MA & & $\mathrm{x}$ & $\mathrm{x}$ & $\mathrm{x}$ & $\mathrm{x}$ & $\mathrm{x}$ & & $\mathrm{x}$ & $\mathrm{x}$ & $\mathrm{x}$ & $\mathrm{x}$ & \\
\hline MG & & & & & $\mathrm{x}$ & $\mathrm{x}$ & $\mathrm{x}$ & & & $\mathrm{x}$ & & \\
\hline \multicolumn{13}{|l|}{ MS } \\
\hline \multicolumn{13}{|l|}{ MT } \\
\hline $\mathbf{P A}$ & & & & & & $\mathrm{x}$ & & & & & & \\
\hline \multicolumn{13}{|l|}{ PB } \\
\hline \multicolumn{13}{|l|}{$\mathbf{P E}$} \\
\hline PI & & & & & & $x$ & & $\mathrm{x}$ & & & & \\
\hline \multicolumn{13}{|l|}{ PR } \\
\hline RJ & & & & & & $\mathrm{x}$ & & & & & & \\
\hline \multicolumn{13}{|l|}{$\mathbf{R N}$} \\
\hline RO & & & & & & & & & & $\mathrm{X}$ & & \\
\hline $\mathbf{R R}$ & $\mathrm{x}$ & & & & & & & & & & & \\
\hline \multicolumn{13}{|l|}{$\mathbf{R S}$} \\
\hline SC & & & & & $\mathrm{x}$ & $\mathrm{x}$ & & & & $\mathrm{X}$ & & \\
\hline \multicolumn{13}{|l|}{ SE } \\
\hline SP & $\mathrm{x}$ & & & & & & & & & & & \\
\hline TO & & & & & & & & & & & & \\
\hline
\end{tabular}

Fonte: elaboração própria. Legenda: Giro do Ativo - GA; Retorno sobre Vendas - RSV; Retorno sobre o Ativo RSA; Retorno sobre o Patrimônio Líquido - RSPL, Imobilização do Patrimônio Líquido - IPL,Participação do Capital de Terceiros - PCT, Composição do Endividamento - CEN. Liquidez Geral - LG; Liquidez Corrente LC; Liquidez Seca - LS, Índice de Cobertura de Juros - ICJ, Capital Circulante Líquido - CCL. UF - Unidade da Federação; AC - Acre; AL - Alagoas; AM - Amazonas; AP - Amapá; BA - Bahia; CE - Ceará; DF - Distrito Federal; ES - Espírito Santo; GO - Goiás; MA - Maranhão; MG - Minas Gerais; MS - Mato Grosso do Sul; MT - Mato Grosso; PA - Pará; PB - Paraíba; PE - Pernambuco; PI - Piauí; PR - Paraná; RJ - Rio de Janeiro; RN Rio Grande do Norte; RO - Rondônia; RR - Roraima; RS - Rio Grande do Sul; SC - Santa Catarina; SE - Sergipe; SP - São Paulo; TO - Tocantins.

Pela análise vertical do Quadro 2, o indicador que acarretou o maior número de resultados insatisfatórios foi o indicador de Participação de Capitais de Terceiros (PCT), o que é perfeitamente compreensível, uma vez que a origem dos recursos do Sistema Sebrae provém de contribuições externas. Avaliando os indicadores por grupo, a maior frequência (13) se resultados insatisfatórios encontra-se em estrutura de capital e solvência, seguido por liquidez e capacidade de pagamento com 8 resultados e lucratividade e desempenho com 6 resultados. 


\section{CONSIDERAÇÕES FINAIS}

Dando continuidade ao estudo de Leão (2017), o presente trabalho objetivou reavaliar a divulgação contábil do Sebrae, bem como analisar os indicadores financeiros dessa entidade, para o período de 2016 a 2018. Como resultado dessa reavaliação, observou-se uma melhora significativa no processo de divulgação das informações decorrente da implementação do portal de transparência da instituição, concluindo que o atual nível de divulgação do Sistema Sebrae torna possível uma leitura contábil da situação econômica e financeira da empresa, assegurando assim o alcance dos outros objetivos desse estudo.

A análise financeira realizada no estudo, como mencionado, possui limitações quanto as particularidades listadas da entidade. Sendo uma entidade sem fins lucrativos e uma empresa que não possui o seu faturamento proveniente de vendas, alguns indicadores foram excluídos desta análise financeira: Saldo de Tesouraria Sobre Vendas - STSV, Ativo sobre Patrimônio Líquido - ASPL, Endividamento Financeiro Sobre Ativo Total - EFSAT, Nível de Desconto de Duplicadas - NDD, Capital Permanente Líquido - CPL, Capital de Giro Próprio - CGP e Capital de Giro Operacional Líquido - CGOL.

Com este estudo é possível concluir, portanto, que o Sistema Sebrae como um todo, encontra-se em uma boa situação financeira. O Sebrae Nacional se destaca em muitos indicadores, justamente por ser a sede do Sistema e com isso obter boa parte dos recursos. Por outro lado, o Sebrae do Maranhão (MA) é a unidade que precisa de mais atenção, uma vez que de 12 indicadores, em 9 apresentou resultados preocupantes. As demais unidades, ou não apresentaram resultados insatisfatórios, ou apresentaram para menos da metade do total de indicadores calculados.

É importante salientar que o Sistema Sebrae, na data do estudo, passa por um momento de transição na esfera contábil. Até o ano de 2018, a instituição utilizava o método de atuação da contabilidade privada, a partir do ano de 2019 com uma determinação do TCU, passa aderir ao modelo de contabilidade do setor público. Com isso, como sugestão para os próximos estudos, é recomendado que se avalie a sua adequação as novas normas, assim como a aplicação deste mesmo estudo, ou de forma semelhante, nas outras entidades do Sistema S. 


\section{REFERÊNCIAS BIBLIOGRÁFICAS}

ALVES, Elder P. Maia. As políticas de estímulo ao empreendedorismo cultural no Brasil o Sebrae como um agente estatal de mercado. Políticas Culturais em Revista, v. 9, nº 2, p. 626-650, 2016.

BARBOSA, Heitor Monteiro. Análise de demonstrativos financeiros como ferramenta para tomada de decisão nas micro e pequenas empresas. Revista Scientia FAER, Olímpia São Paulo, v. 2, p. 38-52, 2010.

CAMPOS, T. M., LIMA, E. O., JÚNIOR V. U., ALVES D. V. Internacionalização de micro e pequenas empresas: um estudo de caso sobre a atuação do Sebrae. Revista da Micro e Pequena Empresa, v.5, no 1, p. 36-50, 2011.

DUQUE, Felipe da Silva. O estudo do Sebrae enquanto difusor junto a noção de "educação empreendedora". In: ENCONTRO DE HISTÓRIA DA ANPUH-RIO, 8., 2018, Rio de Janeiro.

GUimarÃES, Mayhara Dias. GUILlaUMON, Siegrid. Potenciais e limitações do movimento compre do pequeno negócio/Sebrae na Feira do Guará - DF. In: ENCONTRO NACIONAL DOS CURSOS DE GRADUAÇÃO EM ADMINISTRAÇÃO, 28., 2017, Brasília.

LAMACHIA, Leonardo. Imunidade tributária do SEBRAE. Brasília, 2013. 20f. - Artigo (Especialização). Instituto Brasiliense de Direito Público.

LEÃO, Jaqueline de Lima Borges. Análise das demonstrações contábeis do Serviço Brasileiro de Apoio às Micro e Pequenas Empresas - Sebrae. 54p. 2017. Trabalho de conclusão de curso (Monografia - Graduação), Universidade de Brasília, 2017.

LUCENTE, A., BRESSAN, P.. Análise de Índices Financeiros: Estudo de Caso do Sport Club Corinthians Paulista no Período de 2008 a 2013. PODIUM Sport, Leisure and Tourism Review, Vol. 4, N. 3. Setembro/Dezembro. 2015

MARION, José Carlos. Análise das Demonstrações Contábeis: Contabilidade Empresarial. $3^{\text {a }}$ ed. São Paulo: Atlas, 2007.

MARTINS, J. A. F., BEZERRA F. A. O impacto da percepção de importância dos artefatos gerenciais sobre a eficácia na execução orçamentária das unidades do Sebrae. In: CONGRESSO BRASILEIRO DE CUSTOS, 25., 2018, Vitória.

MENDES, P. P., CAVALCANTE JUNIOR, J. R., URBINA, L. M. S, PACHECO, W. S. Análise do conhecimento crítico na promoção da inovação pelo Sebrae. In: SIMPÓSIO DE ENGENHARIA DE PRODUÇÃO DE SERGIPE, 8., 2016, São Cristóvão - Sergipe. 
MILHOMEN, Ana Léa de Vasconcelos. As entidades do sistema "s" (ess) e a obrigação de prestar contas ao Tribunal de Contas da União (TCU). Brasília, 2013. 18f. - Artigo (Especialização) Instituto Brasiliense de Direito Público.

NASCIMENTO, C.; FRANCO, L.M.G; CHEROBIM, A.P.M.S.. Associação Entre Remuneração Variável e Indicadores Financeiros: Evidências do Setor Elétrico. Revista Universo Contábil, Blumenau, v. 8, n. 1, p. 22-36, jan./mar., 2012.

NIQUITO, T. W., ELY, R. A., RIBEIRO, F. G. Avaliação de impacto das assistências técnicas do sistema s no mercado de trabalho. Revista Brasileira de Economia, v. 72. $\mathrm{n}^{\circ}$ 2, p. 196-216, 2018.

OliVEIRA, I., TAVARES, K., SANTANA, R., ARAÚJO, J. G. Micro e pequenos empreendedores e o sebrae: percepção dos empresários e consultores acerca do serviço prestado e especificidades dos negócios. Revista de Micro e Pequenas Empresas e Empreendedorismo da Fatec Osasco, v. 4, n¹, p.198-220, 2018.

PASSAIA, Claudir; Benedito A.; SILVA, Elisângela Maria; DEMOZZI, Marluci. Análise Econômica Financeira com utilização de Índices. Disponível em: <http://uninova.edu.br/Uni/Revista/artigos/artigo03.pdf>. Acessado em: Mar/2019.

PRADO, L. O. C., PAVARINA, P. R. J. P. A atuação do Sebrae-SP na implementação das políticas públicas de desenvolvimento das MPes em Franca (2011-2015). In: SEMINÁRIO INTERNACIONAL DE PESQUISA EM POLÍTICAS PÚBLICAS E DESENVOLVIMENTO SOCIAL. 2., 2015, Franca - São Paulo.

RALIO, Vanise Rafaela Zivieri. DONADONE, Julio Cesar. Estudo sobre o histórico de atuação do Sebrae na consultoria para micro e pequenas empresas brasileiras. Gestão da Produção, Operações e Sistemas, Bauru, v.10, nº 2, p. 33-47, 2015.

REZENDE, I.C.C.; DUARTE, J.M.S; DA SILVA, P.Z.P.; DA SILVA, G.R. Análise da Performance Empresarial da Petrobras: Um estudo sob o enfoque dos indicadores econômico-financeiros. Revista Ambiente Contábil - Universidade Federal do Rio Grande do Norte - ISSN 2176-9036, v. 2, n. 1, p. 54-69, 7 out. 2010.

RIBEIRO, M.G.C; MACEDO, M.A.S.; MARQUES, J.A.V.C.. Análise da relevância de indicadores financeiros e não financeiros na avaliação de desempenho organizacional: Um estudo exploratório no setor brasileiro de distribuição de energia elétrica. Revista de Contabilidade e Organizações, vol. 6 n. 15, p. 60-79, 2012.

SEBRAE. Pequenos negócios em números. Disponível em: <http://www.sebrae.com.br/sites/PortalSebrae/ufs/sp/sebraeaz/pequenos-negocios-emnumeros,12e8794363447510VgnVCM1000004c00210aRCRD> Acessado em: Jan/2019. 
SILVA, José Pereira da. Análise financeira das empresas. 11. Ed. - São Paulo: Atlas, 2012. TEIXEIRA, Lourdes Araújo. Análise financeira na empresa XY: um estudo de caso. 2010. 62 f. Trabalho de Conclusão de Curso (Graduação) - Universidade Federal do Rio Grande do Sul, Porto Alegre, 2010.

TIMOTIO, J. G. M., EÇA, J. P. A., JÚNIOR, I. M. S. Avaliação de desempenho no terceiro setor: um estudo de caso da ong CPCD. Revista de Estudos e Pesquisas Avançadas do Terceiro Setor, v. 4, $\mathrm{n}^{\circ}$ 2, p.412-428, 2017.

TRINDADE, D. P.; DOS SANTOS ClARO, S. J. A. C; TINOCO, J. E. P., SEVERO, P. S. Uso de indicadores financeiros e não financeiros na tomada de decisões gerenciais. Caderno Profissional de Administração da UNIMEP, v. 3, n. 1, 2013.

TRIVIÑOS, Augusto Nibaldo Silva. Introdução à pesquisa em Ciências Sociais: a pesquisa qualitativa em educação. São Paulo: Atlas, 1987.

ZANELLA, Tânia Regina. O Sistema S e a Lei da Transparência. 2012. 19f. Trabalho de Conclusão de Curso (Especialização) - Instituto Brasiliense de Direito Público, Brasília, 2012. 